\title{
Las ciudades hispanas en el siglo III d.C. Un ejemplo: Emerita Augusta
}

\author{
Ma del Rosario Pérez Centeno *
}

\begin{abstract}
RESUMEN
La tradición historiográfica española, establece la decadencia, ruina y abandono de las ciudades hispanas a partir del siglo III d.C.,

basándose en dos hechos fundamentales: las "invasiones" franco-alamanas que asolaron los centros urbanos durante la segunda mitad del siglo III, causando un efecto tan destructor que no consiguieron superar; y el enfrentamiento campo/ciudad. Sin embargo, ninguna de estas teorias ha contado con un análisis detallado de toda la documentación existente, ni ha tenido en cuenta las diferencias regionaies o cronológicas en su globalidad. Un ejemplo de la vitalidad de la mayoría de las ciudades hispanas en el siglo III d.C. lo tenemos en Emerita Augusta.

\section{ABSTRACT}

The decadence and ruin of cities in Roman Spain since Third Century A.C. is a triditional idea in our historiography. This statement is based ou two facts: the frank and alaman invasions, and the country/city fighting duality. But a study in detail of the sources, taking into account the regional and cronological differences, shows the strong life of most spanish cities in Third Century A.D., such as Emerita Augusta.
\end{abstract}

* Universidad de Valladolid. 
Enclavada en un sitio privilegiado en un declive del río Guadiana, lo que permite un mejor acceso, y ceñida al norte por el arroyo Albarregas, Augusta Emerita ", nace en función de esa posición estratégica junto al puente sobre el Guadiana, punto de confluencia de las calzadas procedentes del suroeste peninsular y que se dirigían tanto a los distritos mineros del noroeste, como al interior de la Meseta, comunicándola con las capitales de las otras dos provincias hispanas: Corduba y Tarraco?

Su origen tuvo un claro componente militar ya que fue poblada por veteranos de las legiones $V$ Alaudae, $X$ Gemina, y posiblemente, $X X$ Victrix, pero también por familias itálicas que vinieron poco a poco a engrosar la población de la nueva colonia ${ }^{3}$, junto a antiguos pobladores de la zona ${ }^{4}$. A la nueva colonia se la dotó de un amplio territorio, lo que unido al favor de la administración romana, permitió su desarrollo urbano, sobre todo en época flavia, dinastía que patrocinó muchos proyectos urbanísticos, como el teatro y el foro ${ }^{5}$, junto a la iniciativa particular que levantó sus casas sin escatimar lujos y magnificencia; este esplendor continuo en época antonina y durante el siglo III d.C., no pudiéndose apreciar síntomas de que la ciudad sufriera la crisis que se percibe en otros núcleos; es más, durante el siglo IV se convierte en una de las ciudades más populosas de su tiempo ${ }^{6}$, convirtiéndose en un centro administrativo y político de primer orden.

El trazado urbano de Emerita fue planificado en todos sus detalles desde su origen; el punto de arranque fue el puente sobre el Guadiana que se prolonga en el decumanus maximus, mientras que otro puente, el levantado sobre el arroyo Albarregas, es el final del kardo maximus, a partir de estos dos ejes se estructura la red urbana, con calles regularmente establecidas, flanqueadas por pórticos ${ }^{7}$. La ciudad contaba con dos foros, el primero, en el ángulo noreste de la ciudad, estaba presidido por el templo de Diana ${ }^{8}$; el

It. $414,1.415,2-3.416,3-4.418,6-7.419,8.420,7.431,9.432,8.433,1.438 .444,3$; Rav. IV $44(314,5.314,11.314,19-20.315,7.316,2-3)$. IV $45(319,16)$; It. Astorga III; Strab. III 2, 15. 4, 20; Ptol. II 5, 6; Cass. Dio LIII 26; Mela II 88; Plin. IV 117; Front. agrim. I, 51, 20; Hygin. 171; Polem. Silv. 131, 11; Prud. peristeph. III 186; Tac. hist. I 78; Isid. orig. 15, 1, 69; Chronicae y concilia, passim. CIL II, 32. 371. 492. 484. 494. 505-508. 823. 824. 1056. 5212. 5270. 5458.

2 J.M. Alvarez Martinez, El Puente y el urbanismo de Augusta Emerita, Madrid 1981, 57 ss

3 G. Fonnl, "La popolazione di Augusta Emerita", Homenaje a Sáenz de Buruaga, Badajoz, $1982,69$.

" J.M. Alvarez Martinez, "Consideraciones sobre la Mérida prerromana", R.E.E., 1984, 101 ss.

5 W. TriLLMICH, "Colonia Augusta Emerita, die Haupstadt von Lusitanien», Stadtbild und Ideologie, 1990, 299 ss.

Aus. Ordo urbilium nobilium XIX, 83.

J.M. Alvarez Martinez, op. cit. 1981, 229-236.

\& J.M. Alvarez Martinez, "El Foro de Augusta Emerita", Homenaje a Sáenz de Buruaga, Badajoz 1982, 53 ss. 
otro foro, posiblemente de carácter provincial, se localiza en la actual plaza del Parador de Turismo, en el que también aparecieron las ruinas de un templo ${ }^{9}$; de este foro proviene un pedestal dedicado a Galieno ${ }^{10}$, de mármol blanco, del año 261 d.C.

Otros edificios monumentales se conservan aún en Mérida. En la periferia, ubicado en el extremo suroriental, se halla el conjunto formado por el teatro y el anfiteatro, ambos de los últimos años del cambio de Era ${ }^{11}$. El anfiteatro presenta una estructura compleja, de transición entre los tallados en el suelo natural y los levantados en obra con estructuras huecas ${ }^{12}$; se sitúa bordeando la muralla, de época anterior a la construcción del anfiteatro, apoyándose claramente sobre ella, usándola como cimbra en el punto donde el anfiteatro tocaba el interior de esta muralla ${ }^{13}$. También sobresale el puente sobre el Guadiana, que consta de dos tramos de arquatrones con un malecón entre ambos para protegerlo de las fuertes avenidas del río ${ }^{14}$.

El sistema de abastecimiento de agua contaba con tres acueductos provenientes de distintos embalses de los alrededores de la ciudad ${ }^{15}$; el más espectacular, sin duda, es el de "Los Milagros", proveniente del embalse de Proserpina que cuenta con un dique de 500 metros de longitud, y que, a través de una excelente fábrica, bastante bien conservada, llegaba a la ciudad por lo que hoy es el cementerio, concluyendo en el depósito del cerro de El Calvario ${ }^{16}$.

Durante los últimos años se han ido produciendo noticias sobre la aparición de restos de muralla en diversos lugares del casco urbano de Mérida: detras de la Casa del Anfiteatro, en la calle Obispo Masona, en

9 J.M. Alvarez Martínez, "La época romana", en Historia de la Baja Extremadura, Badajoz 1986,89

10 J.L. Ramirez Sadaba y otros, "Un nuevo pedestal de Galieno encontrado en Mérida", Anas, $6,1993,75-84$

11 W. Trillmich, «Colonia Augusta Emerita, die Haupstadt von Lusitanien», Stadtbild und ldeologie, 1990,87 ss.

12 J.C. Golvin, L'amphithéâtre romain. Essai sur la théorisation de sa forme et des ses fonctions, París 1988, t. I, 109-111.

13 M. BENDALA / R. DURAN, «El anfiteatro de Augusta Emerita: rasgos arquitectónicos y problemática urbanística y cronológica", Coloquio Int. El Anfiteatro en la Hispania Romana, Mérida, 1992 (1994), 247 ss.

J.M. Alvarez Martínez, op. cit. 1981, 163-168.

15 A. Jiménez Martín, "Los acueductos de Augusta Emerita», en Augusta Emerita, Madrid 1976,111

16 J.M. Alvarez Martínez, "En torno al acueducto de "Los Milagros" de Mérida", Segovia y la Arqueología Romana, Barcelona 1977, 49 ss; A.M. Canto de Gregorio, "Sobre la cronología augustea del acueducto de "Los Milagro" de Mérida”, Homenaje a Sáenz de Buruaga, Badajoz 1982, $157-176$ 
la Puerta de la Villa, en distintos puntos de la Alcazaba,.. ${ }^{17}$, poniendo de relieve la existencia de dos recintos amurallados adosados, el recinto interior parece de época augustea, cuando se levantó el plano de la ciudad, está realizado en opus incertum; el exterior, que refuerza el anterior con un paramento de opus quadratum y un relleno de tierra y piedras, sería de época bajo imperial, aunque no se puede precisar su cronología ${ }^{18}$.

La arquitectura doméstica también cuenta con numerosos restos. En el número 26 de la actual calle Suárez Somonte apareció una domus con restos de pintura mural y mosaicos en el subsuelo de la vivienda ${ }^{19}$; las pinturas pueden datarse a finales del siglo III o primer cuarto del siglo iv d.C., existiendo evidencias de pinturas anteriores; el mosaico es anterior pues se introduce por debajo de los muros, datándose en el siglo III d.C. Junto a la postcaena del teatro se localiza otra domus, que debe corresponder a un momento de abandono del teatro o por lo menos de alguna de sus dependencias; la casa fue construida ${ }^{20}$ con materiales y aparejos pobres, en parte reaprovechados de una dependencia del teatro; presenta suelos de mosaico que corresponden a los siglos $\mid 1$ y $\|$ Il d.C. Al pie de la actual Plaza de Toros se localiza la villa de «San Alvin», donde se localiza el famoso mosaico cosmogónico cuya cronología ha sido muy discutida ${ }^{21}$. Detras de la Plaza de Toros, fuera del recinto amurallado, se localiza la denominada "Casa del Mitreo" que presenta varias habitaciones pavimentacias con mosaico, uno de ellos, localizado en el corredor, de tema geométrico, ha sido fechado ${ }^{22}$ en el siglo III d.C., al igual que el decorado ${ }^{23}$ con cuatro cráteras. La denominada "Casa del Anfiteatro" por estar en sus proximidades, se ubica junto al acueducto de San Lázaro y fuera de las murallas; debió construirse a finales del siglo I d.C., siendo abandonada

17 M. Almagro BASCH, «La topografía de Augusta Emerita», Symposio de Ciudades Augusteas, Zaragoza 1976, 189-211; J.M. Alvarez MARTinez, "Excavaciones en Augusta Emerita», Arqueología de Ciudades Modernas Superpuestas a las Antiguas, Zaragoza 1983 (1985), 35-53.

18 A. BALIL, "La defensa de Hispania en el Bajo Imperio", Zephyrus, XI, 1960, 179-97; C. FERNÁNDEZ OCHOA / A. MORILlo, «Fortificaciones urbanas de época bajoimperial en Hispania. Una aproximación crítica. II", CU.P.A.U.A.M., 19, 1992, 319-320.

19 J. Alvarez Saenz de Buhuaga, "Una casa romana con valiosas pinturas de Mérida", Habis, $5,1974,169-187$.

20 A. BAL!L, «Sobre la arquitectura doméstica de Emérita", Actas del Bimilenario de Mérida, Mérida 1976, 80-85.

21 E. García Sandoval, «El mosaico cosmogónico de Mérida», XI C.N.A., Mérida 1968 (1970), 743 , considera que debe fecharse a finales del siglo 11 o principios del III d.C., es decir en época severiana; sin embargo J.M. Blázquez, Mosaicos romanos de España, Madrid 1993, 471, cree que es posterior, fechándolo en el siglo iv d.C.

22 J.M. BLÁZQUEZ, op. cit., 1993, 473.

23 J.M. BLAZQUEZ, op. cit., 1993, 472. 
a mediados del siglo III, aspecto que algunos autores ${ }^{24}$ achacan a las invasiones de dicho momento, lo cual parece de todo punto imposible, ya que no hay ningún testimonio que permita suponer la presencia invasora en esta zona de la Península; presenta una estructura con atrio y peristilo, con pavimentos de mosaico en todas sus habitaciones y pinturas murales; un mosaico con tema de peces cubría el suelo del tablinium, habiendo sido fechado ${ }^{25}$ a partir del 235 d.C. Algunas de las pinturas murales están realizadas con la técnica de crustae, con la que se trata de imitar las calidades del mármol, teniendo su época de mayor auge a partir del siglo III d.C., momento al que seguramente pertenecen ${ }^{26}$ las de la Casa del Anfiteatro.

La vida urbana era floreciente, habiéndose formado una clase social acomodada y deseosa de adquirir obras de arte, como demuestra el hecho de que los talleres de escultura florecieran en la ciudad y no dieran a basto con las demandas de los ciudadanos a lo largo de los primeros siglos del Imperio, creando una escuela propia de gran cateogría ${ }^{27}$. El siglo III no significa un cambio brusco en los talleres locales, continuando la tradición retratística de los monumentos funerarios, como en épocas anteriores, no es hasta finales de siglo, o ya en el siguiente, cuando se produce el final del retrato escultórico en Mérida, al igual que en el resto de la Península, debido a un cambio de mentalidad y de gusto estético de la población del Bajo Imperio ${ }^{28}$. En el siglo III no se producen transformaciones destacables, únicamente algunos cambios en los retratos que se adaptan a los nuevos gustos de la moda, como se puede apreciar en la magnífica estela ${ }^{29}$ de $L$. Antestius Persicus, en la que los elementos arquitectónicos que enmarcan la figura apenas tienen relevancia, siendo la imagen del difunto la que sobresale, mostrando a un varón de recias facciones, grandes orejas y un sencillo peinado, llevando como indumentaria la toga contabulata, característica de la moda masculina en tiempos de Filipo I, momento en que se fecha el monumento. En el Museo de la ciudad se conserva una cabeza-retrato, mayor del natural y con apéndice cónico para acoplar a

\footnotetext{
24 E. García SANDOVAL, "informe sobre las casas romanas de Mérida y excavaciones en la 'Casa del Anfiteatro", E.A.E., 49, 13-43.

25 A. Blanco FreiJerio, «Mosaicos romanos de Mérida», C.M.E., I, 1978, 43, n. 31 .

26 L. ABAD CASAL, «Las imitaciones de crustae en la pintura mural romana en España», A.E.A., 135-138, 1977-78, 189.

27 T. Nogales Basarrate, «El retrato privado emeritense: estado de la cuestión", Actas I Reunión sobre Escultura romana en Hispania, Mérida, 1993, 141 ss.

28 J. ARCE, «Retratos imperiales de época tardía en Hispania», Retratos antiguos de Yugoslavia, Barcelona 1989, 177 ss.

29 A. Garcia Bellido, Esculturas romanas de España y Portugal, Madrid 1949, n. 285.
} 
un cuerpo, por lo que podría tratarse de un retrato oficial de algún emperador, es de una gran calidad y el tipo de peinado inclina a fecharla ${ }^{30}$ en el segundo cuarto del siglo III d.C. Así mismo, de este mismo siglo parecen varios fragmentos con retratos que pudieran pertenecer a sarcófagos, 10 que vendría a demostrar que Emerita estaba en sintonía con el resto del territorio peninsular, ya que hasta hace poco sólo se había documentado un fragmento de sarcófago entre los restos de la ciudad ${ }^{31}$

Una serie de restos materiales dispersos fechados en el siglo III demuestran la vitalidad del comercio de la ciudad durante este momento; en las inmediaciones del Puente Romano sobre el Guadiana, apareció un balsamario ${ }^{32}$ que reproduce un busto varonil, con los rasgos étnicos de un nubio o etíope, bigote y barba poco espesa, cabellera rizada muy cuidada, encima de los temporales lleva dos anillas fijas a las que va engarzada un asa móvil que termina en sendos prótomos de aves. De un lugar sin determinar procede una muñeca ${ }^{33}$ articulada, de hueso, a la que le faltan los brazos y las piernas, presenta un peinado muy rústico, indicado con incisión, al igual que el rostro, los senos y el sexo, fechándose en la segunda mitad del siglo III. En la colección de glíptica de la Fundación Alhonoz, se conserva un camafeo ${ }^{34}$ decorado con tema de circo, procedente de Emerita.

Por otra parte, se encuentran también las producciones cerámicas típicas del siglo III, en su mayoría son piezas importadas procedentes de Africa ${ }^{35}$ como la sigillata clara $A$, cuya presencia es escasa en relación con otros yacimientos del sur peninsular, predominando las formas decoradas de la primera mitad del siglo III, a partir de ese momento comienzan a abundar los ejemplares de sigillata clara C, fabricada en Túnez, siendo su proporción en Mérida muy importante, perdurando hasta comienzos del siglo IV d.C. Del siglo III se documenta además una lucerna ${ }^{36}$ en forma de recipiente cuadrangular, con cuatro orificios para la colocación de mechas.

Las piezas de vidrio halladas en Augusta Emerita son de una gran calidad, contando con un repertorio que va desde el siglo I al IV d.C., predominando los utensilios domésticos o ungüentarios, siendo la mayoría de talleres locales que estarían ubicados en barrios industriales suburbanos,

T. Nogales Basarfate, op. cit. 1993, 151.

A. Garcia Bellido, op. cit. 1949 , n.․․ 266.

S.F. POzO, «Balsamarios antropomorfos en bronce de época romana hallados en Hispania», A.E.A., 61, 1988, 286-288

33 A. BALIL, "Muñecas antiguas en España», A.E.A., 105-106, 1962, 82.

34 A. Rodriguez Morales, "Un camafeo con la representación de una carrera de carros en el circo", Anas, IV-V, 1991-92, 175-180.

35 A. Vazquez de la Cueva, Sigillata Africana en Augusta Emerita, Mérida 1985, 31 ss.

36 O. GlL FARRES, "Otra curiosa lucerna inédita del Museo Emeritense», M.M.A.P., VII, 1947, 44-45. 
que empleaban la técnica del soplado, produciendo formas extrañas, de una gran calidad por lo que abastecían un mercado de lujo que llegaba hasta el sur de Francia y el norte de Italia ${ }^{37}$, y a centros hispanos como Carmo o Italica. En el siglo III parece que se produce un bache en la producción, que es escasa y de peor calidad ${ }^{38}$, aunque vuelve a renacer en el siglo IV d.C.; restos de una botella de vidrio de color amarillo pálido, decorada con círculos, y fechados ${ }^{39}$ en el siglo III d.C., aparecieron en la tumba de una necrópolis de Mérida.

Como era norma general en el Imperio, las necrópolis se encontraban fuera del recinto urbano, en los márgenes de las calzadas que partían de la ciudad; en Mérida se documentan ${ }^{40}$ dos necrópolis, una al Norte que corresponde con las actuales calles Furnier, Calvarios, Constantino y Pancaliente, cuyos monumentos se datan entre mediados del siglo $\mid 1$ y fines del III d.C., presentando estelas funerarias caracterizadas por un nicho con arco escarzano, rara vez cerrado a dintel, flanqueado por columnas de esquina, o con pilastras adosadas, siendo obras locales, de buena calidad ${ }^{41}$. La otra necrópolis se localiza en el sector SE y oriental, coincidiendo con la actual Avenida de Juan Carlos I, antigua vía hacia Caesaraugusta, y junto al arroyo Albarregas, llegando a alcanzar las cercanías del circo, siendo por tanto una de las áreas funerarias más importantes de la colonia; está compuesta por cinco mausoleos y unas cincuenta y ocho tumbas, entre las que predominan las cie inhumación; los mausoleos presentan ${ }^{42}$ una disposición regular, estando alineados con la antigua calzada romana, fechándose entre fines del siglo । e inicios del II d.C., en un momento indeterminado fueron desmantelados, siendo sus materiales reaprovechados en la construcción de algunas de las tumbas aparecidas en el solar durante los siglos III y IV d.C. Las tumbas aparecieron diseminadas en todas direcciones, sin tener un eje de ordenación, y con una tipología muy diversa ${ }^{43}$; sus estructuras eran muy pobres, al igual que sus ajuares, que permiten datar los enterramientos entre la segunda mitad del siglo 111 y el IV d.C., predominan los elementos de uso doméstico como jarras, platos, vi-

37 Ma P. Caldoera de CASTro, "Aspectos del vidrio romano en Mérida", Homenaje a Sáenz de Buruaga, Madrid 1982, 137-144.

$38 \mathrm{M}^{2} \mathrm{P}$. Caldera / A. VelÁzQuez, “Augusta Emerita I", E.A.E., 126, 53-72.

J. Price, Roman Glass in Spain, Bostón 1990, t. I, 341.

M. Bendala Galan, "Las necrópolis de Mérida", Actas del Bimilenario de Mérida, Madrid $1976,148-149$

A. Garcia Bellido, op. cit. 1949, 286-287.

A. GARCiA BelLiDo, "La gran necrópolis romana de la salida del puente», E.A.E., 11, 1962, 7 ss.

J.L. RAMíREz SÁDABA / E. GIJÓN, «Las inscripciones de la necrópolis del Albarregas (Mérida) y su contexto arqueológico", Veleia, 11, 1994, 117-167. 
drios, y algunas monedas, como una de Claudio II hallada en una fosa rectangular realizada con ladrillos reutilizados. La necrópolis ha proporcionado un buen número de inscripciones, la mayoría fechadas en el siglo IV d.C. ${ }^{44}$, aunque también hemos documentado alguna perteneciente al siglo III d.C., que nos permite conocer el nombre de dos magistrados municipales, el primero es $C$. Titius Similis, originario de Colonia (Germania), que fue procurator provincia Lusitaniae et Vettoniae, y al mismo tiempo curator reipublica Emeritensis, durante la primera mitad del siglo III d.C. ${ }^{45}$; el otro es $L$. Antestius Persicus, originario de la ciudad, donde desempeñó los cargos de duoviri y pontifex perpetuus, a mediados del siglo III d.C., murió a los 37 años, realizando el monumento en su honor ${ }^{46}$ sus hijos lulia Persilla y Antestius Autianus. De origen africano, concretamente de Madaura, era Antonius Saturninus, que posiblemente se casó en Emerita con una originaria de la ciudad, Ulpia luniana; ambos se hicieron construir una estela de mármol blanco, en la que aparece la figura del difunto, vestido con toga y con las pupilas y el iris muy grabados, lo que da una fecha del siglo ill d.C. para la obra, de un taller local ${ }^{47}$. Interanniensis era Q. Licinius Paternus, difunto de 75 años, a quien dedican la inscripción ${ }^{48}$ su hija Licinia Paterna y su esposa Licinia Flavina. Un soldado de Legio VII, Geminius Garcilianus, dedicó un epígrafe ${ }^{49}$ a su esposa Minicia Paterna, muerta a los 35 años de edad. Los escasos datos que nos aportan estas incripciones permiten ver el cosmopolitismo de Emerita, dado el elevado porcentaje de extranjeros que aparecen en ellas, provenientes de zonas tan alejadas del Imperio como Germania Inferior. También podemos constatar el mantenimiento de la estructura municipal a través del desempeño de cargos como duovir o curator, y la pérdida de la denominación de colonia que poseía la ciudad, por el de reipublica, aspecto general de las ciudades del siglo III d.C.

Al contrario que en las otras capitales provinciales, en Emerita apenas han aparecido manifestaciones del culto imperial, lo que no significa que no existiera, sino que no se han encontrado testimonios que lo ratifiquen, tan sólo se ha documentado el ya mencionado pedestal dedicado al emperador Galieno, que presenta dammatio memoriae, aunque puede entenderse su praenomen y nomen, fechado en el año 261 d.C. por la tribu-

\footnotetext{
44 J.L. RAmírez SÁdABA, "Recientes hallazgos epigráficos de los siglos IV-VII d.C. en Augusta Emerita», III Congreso Andaluz de Estudios Clásicos, Sevilla 1994, 124 ss.

45 CIL H, 484.

AE, $1952,117$.

A. Garcia Bellido, op. cit. 1949, 293-294.

CIL II, 511 .

A. García Bellido, op. cit. 1949, n. 290
} 
nicia potestas y el consulado, y fue dedicado por el legatus Augustorum pro praetore $P$. Clodius Laetus Macrinus, confirmando la vitalidad de la ciudad como capital de Lusitania, tema que se había puesto en entredicho ${ }^{50}$.

Contamos con un único testimonio epigráfico sobre la religiosidad de los emeritenses, se trata de una tabula ansata de estuco pintado en rojo con las letras en blanco, localizada originariamente en la pared derecha de la entrada norte del anfiteatro, estando dedicada a la diosa Caelestis $\mathrm{Ne}$ mesis, habiendo sido fechada ${ }^{51}$ a comienzos del siglo III d.C.; el dedicante sería M. Aurelius Felix, originario de Roma. La asociación de las diosas Caelestis y Nemesis en el sacellun de un anfiteatro también se produce en Italica. A mediados del siglo III d.C. contaba también con una comunidad cristiana, según se desprende de la carta 67 del obispo de Cartago, San Cipriano, mencionando los obispados de Asturica-Legio, Emerita y Caesaraugusta ${ }^{52}$, y concretamente al obispo de Emerita, Marcial, que es destituido por haber rendido culto a los dioses paganos, nombrando en su lugar a Felix; estos hechos ocurren entre los años 254 y 258 d.C., para algunos autores ${ }^{53}$ el hecho de que en esta carta no se mencione que Marcial era el primer obispo de la ciudad, significa que habrían existido otros con anterioridad, lo cual sólo es una teoría y no permite conocer con seguridad la antigüedad de la sede episcopal de Mérida.

El territorium de Augusta Emerita fue tan extenso que los gromáticos de la época lo ponían como ejemplo en sus obras ${ }^{54}$, pudiendo señalar sus límites, aunque siempre teniendo en cuenta el carácter discontinuo de los territoria de las ciudades romanas, por el sur las civitates de los conventos cordubensis e hispalensis: Lacinimurga, lulipa, Municipium lulium, Regina, Curiga, Nertobriga y Seria; por el norte, Norba; por oriente, Valdecaballeros; y por occidente, Borba Estremoz, coincidiendo con el territorium de Ebora ${ }^{55}$. Este amplísimo territorio comprendía ${ }^{56}$ varios núcleos de población importantes, unidos a la colonia a través de vías, oficiales o se-

5o A. CANTO, "Colonia lulia Augusta Emerita: consideraciones en torno a su fundación y territorio", Gerión, 7, 1989, 179 ss.

51 M.C. Marín Ceballos, "Dea Caelestis en la epigrafía hispana", / Congreso Peninsular de Historia Antigua, Coimbra 1993, 840-842.

52 Cipriano, Epist. 67, VI, 1.

53 A. QuinTANA PRIETO, "La cristianización en Astorga", I Congreso Internacional Astorga Romana, Astorga 1986, 92 ss; A. Velado Graña, «La carta sinodal de San Cipriano y otros 36 obispos africanos a las comunidades cristianas de Astorga-León y Mérida", Congreso Internacional Astorga Romana, Astorga 1986, 289 ss.

54 Frontino, De contr. agr. 37, 13; Hyginio, De limit. const. 136.

55 A. CANTO, Op. cit. $1989,140-205$.

56 J.M. Alvarez Martínez, op. cit. 1986, 89-185. 
cundarias; un extenso bosque dedicado a la diosa Feronia, localizado en la zona de Montánchez-Alcuéstar ${ }^{57}$; asi como un importante asentamiento rural, con villae de considerable entidad ${ }^{58}$, sobre todo las que están en las proximidades de Emerita. Como la gran villa rústica situada junto a la calzada de Emerita a Olisipo, conocida como «El Hinojal», en la Dehesa de Las Tiendas, que data del siglo II pero cuyas principales edificaciones no se realizaron hasta la segunda mitad del siglo III o comienzos del IV, siendo este último siglo el de mayor auge de la villa ${ }^{59}$. O la localizada en la Dehesa de la Cocosa, a unos 16 kilómetros al sur de Badajoz, cuyos restos ocupan una gran extensión ${ }^{60}$, con abundantes tejas, ladrillos y baldosas; su fundación se produciría a mediados del siglo I d.C. sufriendo continuos cambios y mejoras, pero manteniéndose hasta la Edad Media. En el término de Valencia de Alcántara se documentan restos de una villa, de la que se conserva un mosaico ${ }^{51}$ en el que se representaba una escena con el triunfo de Baco, pero de la que sólo se puede apreciar algunos fragmentos; estilísticamente su fecha no debe sobrepasar el siglo III d.C. En las proximidades se halló un ara ${ }^{62}$ dedicada a Júpiter Optimus Maximus, por una mujer de onomástica indígena, Aleba Celti $f$.

Entre los núcleos de población cabe señalar Alange, identificado con la importante estación termal de Aquae, localizada a unos dieciocho kilómetros al SE de Mérida; el núcleo en torno a la termas debió ser pequeño, pero muy frecuentado dada la proximidad de la colonia; estaba unida a Mérida a través de una calzada que salvaba el río Matachel ${ }^{63}$; en las proximidades se encontró un ara votiva de mármol blanco, dedicada a luno Regina, por el senador Licinius Serenianus y su esposa Varinia Etaccina, también del orden senatorial, por la salud de su hija Varinia Serena. Licinius Serenianus sería senador en la época de Severo Alejandro, ocupando el cargo de leg. propraetore Capadociae, con Maximino; el ara es el único elemento cronológico para fechar las termas, ofreciendo una referencia ante quem ${ }^{64}$.

57 M.P. Garcia Bellido, «Las religiones orientales en la Península lbérica: Documentos numismáticos |», A.E.A., 64, 1991, 73-75.

58 J.G. Gorges, Les villes hispano-romaines, París 1979, 189 ss; Idem, "Villes et villas de Lusitanie. Intéraction-échanges-autonomies", Les villes de Lusitanie romaine, París, 1990, 91 ss.

59 J.M. Alvarez Martínez, "La villa romana de "El Hinojal" en la Dehesa de "Las Tiendas" (Mérida)», N.A.H.Arq. 4, Madrid 1976, 459 ss.

60 J. Serra Ráfols, La villa romana de la Dehesa de "La Cocosa", Badajoz 1952, 19 ss.

61 J.M. BLAZOUEZ y otros, "Hallazgos de mosaicos romanos en Hispania (1977-1987)", E.T.F., $6,1993,284-286$.

62 CIL II, 755

63 G. MORA, «Las Termas romanas en Hispania», A.E.A., 143-144, 1981, 55-56.

64 J.M. Alvarez Martinez, "Las termas romanas de Alange", Habis, 3, 1973, 286-290. 
Otro núcleo importante era Turgalium, identificada con Trujillo, que era una de las tres praefecturae de Emerita ${ }^{65}$; el territorium de la prefectura comprendería los actuales términos municipales de: Trujillo, Garciaz, Robledillo de Trujillo, Salvatierra de Santiago, Santa Ana, Ibahernando, Santa Marta de Magasca, Plasenzuela, Zorita, Villamesias, Torre de Santa María, Herguijuela, Santa Cruz de la Sierra, Conquista de la Sierra, Valdefuentes y Abertura, es decir, desde quince kilómetros al norte del Guadiana hasta Turgalium, como parecen demostrar los termini de Valdecaballeros ${ }^{66}$; en todo este amplio territorio han aparecido un buen número de inscripciones, de las que al menos cincuenta y cuatro han sido datadas en el siglo 111 d.C.

La prefectura meridional está atestiguada por los termini de Montemolín y Valencia del Ventoso, que incluyen los núcleos de Curiga, identificada con Monesterio ${ }^{67}$, y Ugultunia, situada en Medina de las Torres ${ }^{68}$, donde se ha recuperado un buen conjunto epigráfico.

Otro de los núcleos de población que quedaba dentro del territorium de Emerita era la mansión de la vía de la Plata Ad Sorores ${ }^{69}$, ubicada en el actual pueblo de Casas de Don Antonio, o más precisamente en la dehesa de Santiago de Bencáliz, en las estribaciones de la Sierra de San Pedro, donde se localizan los restos de una villa monumental ${ }^{70}$, de complicada estructura, que fue reformada a mediados del siglo iv d.C., convirtiendo el peristilo del siglo III, de forma rectangular, en una habitación absidiada. En las proxinidades de la vía, antes de llegar a la mansión, en el actual término municipal de Alcuéscar, concretamente a tres kilómetros y medio al sur del pueblo, se localizan los restos de una iglesia visigótica abandonada; las excavaciones realizadas en ella ${ }^{71}$ pusieron al descubierto una serie de estructuras anexas anteriores, que abarcaban un período cronológico muy amplio viniendo de época romana, cronología confirmada por un buen número de inscripciones de esta época, tanto votivas como funerarias. Se han localizado un total de 48 inscripciones, 17 de ellas votivas, de las que trece están dedicadas a la diosa indígena Ataecina, por lo

65 Hyg. De limit. const. 136.

66 A. CANTO, op. cit. $1989,176$.

67 J. Garcia lglesias, "La Beturia, un problema geográfico de la Hispania antigua", A.E.A., XLIV, 1971, 89 sS.

68 G. Rodriguez Bordallo-Rios, «Contributa Iulia Ugultuniacum», V C.E.E., Badajoz, 1976, 150 ss.

69 it. 433, 3; Rav. IV 45, 15.

70 A. ALONSO SÁNCHEZ, "Las estancias absidiadas en las villae romanas de Extremadura», Norba, IV, 1983, 203.

71 L. Caballero Zoreda y otros, "La iglesia de época visigoda de Santa Lucía del Trampal. Alcuéstar (Cáceres)", Extremadura Arqueológica, 2, 1991, 510 ss. 
que se ha pensado que la iglesia podía haber sido un antiguo santuario indígena, romanizado, en el que además de rendir culto a esta divinidad, se daria culto a dioses romanos como Júpiter y los Lares, durante todo el Imperio ${ }^{72}$; todo ello pudo formar parte de un asentamiento romano que no estaría lejos de las ermitas de Santa Lucía y de Santiago, y que podría ser el yacimiento de San Jorge, localizado entre ellas dos, y todo dentro del territorium de Augusta Emerita.

Las ciudades hispanas del siglo III, por tanto, mantenían su vitalidad. Contaban con una red viaria en buen estado, gracias a las sucesivas reparaciones durante todo el período. Disfrutaban de un elevado urbanismo, financiado en épocas anteriores, que ahora han de mantener. Sus élites locales siguen activas, acaparando grandes fortunas por la explotación de la tierra, y controlando la vida municipal. La ciudad hispana del siglo III d.C. se mantiene como sede de la administración y del gobierno del territorio, así como centro del culto oficial y de las distintas manifestaciones religiosas, además de como centro de producción y artesanado, continuando con una intensa actividad comercial No se puede hablar de disociación entre la ciudad y el campo, ni de un abandono de la ciudad por el campo, sino de un uso alternativo de ambos. En definitiva, durante el siglo III d.C. la mayoría de las ciudades hispanas se transforman, no desaparecen ni se arruinan, como hemos podido comprobrar en el caso de Emerita Augusta. 